\title{
Twenty-first century wave climate projections for Ireland and surface winds in the North Atlantic Ocean
}

\author{
Sarah Gallagher ${ }^{1}$, Emily Gleeson $^{1}$, Roxana Tiron$^{2}$, Ray McGrath $^{1}$, and Frédéric Dias ${ }^{3}$ \\ ${ }^{1}$ Research, Environment and Applications Division, Met Éireann, Glasnevin Hill, Glasnevin, Dublin 9, Ireland \\ ${ }^{2}$ OpenHydro Ltd., Greenore, Co. Louth, Ireland \\ ${ }^{3}$ UCD School of Mathematics and Statistics, University College Dublin, Belfield, Dublin 4, Ireland \\ Correspondence to: Sarah Gallagher (sarah.gallagher@met.ie)
}

Received: 11 January 2016 - Revised: 14 April 2016 - Accepted: 19 April 2016 - Published: 26 April 2016

\begin{abstract}
Ireland has a highly energetic wave and wind climate, and is therefore uniquely placed in terms of its ocean renewable energy resource. The socio-economic importance of the marine resource to Ireland makes it critical to quantify how the wave and wind climate may change in the future due to global climate change. Projected changes in winds, ocean waves and the frequency and severity of extreme weather events should be carefully assessed for long-term marine and coastal planning. We derived an ensemble of future wave climate projections for Ireland using the EC-Earth global climate model and the WAVEWATCH III ${ }^{\circledR}$ wave model, by comparing the future 30-year period 2070-2099 to the period 1980-2009 for the RCP4.5 and the RCP8.5 forcing scenarios. This dataset is currently the highest resolution wave projection dataset available for Ireland. The ECEarth ensemble predicts decreases in mean (up to $2 \%$ for RCP4.5 and up to $3.5 \%$ for RCP8.5) $10 \mathrm{~m}$ wind speeds over the North Atlantic Ocean $\left(5-75^{\circ} \mathrm{N}, 0-80^{\circ} \mathrm{W}\right)$ by the end of the century, which will consequently affect swell generation for the Irish wave climate. The WAVEWATCH III ${ }^{\circledR}$ model predicts an overall decrease in annual and seasonal mean significant wave heights around Ireland, with the largest decreases in summer (up to $15 \%$ ) and winter (up to $10 \%$ ) for RCP8.5. Projected decreases in mean significant wave heights for spring and autumn were found to be small for both forcing scenarios (less than $5 \%$ ), with no significant decrease found for RCP4.5 off the west coast in those seasons.
\end{abstract}

\section{Introduction}

Due to its location in the North Atlantic Ocean, Ireland is advantageously placed in Europe from a renewable wind and wave energy perspective. The west coast consists of an energetic and variable wind and wave climate which consequently has a large potential for renewable energy extraction (Gallagher et al., 2016a), and is a promising location for the deployment of future Wave Energy Converters (WECs). Ireland is also regularly in the path of energetic swells and midlatitude cyclones, a concern for public safety in the coastal and marine environment, and the viability of any potential WECs deployment. The prevailing wind directions are from the south and west with annual mean surface $(10 \mathrm{~m})$ wind speeds in the offshore of 5-10 $\mathrm{m} \mathrm{s}^{-1}$. Annual mean significant wave heights (SWH) vary from $1-2 \mathrm{~m}$ in the wind-sea dominated Irish Sea, to 3-4 m off the swell dominated At- lantic coast of Ireland. In winter mean SWHs are over $5 \mathrm{~m}$ off the west coast (Gallagher et al., 2014). Although not part of this study, the careful assessment of any potential WECs deployment locations would also benefit from the consideration of currents, in addition to the wind and wave climate, and in particular wave-current interactions (WCI), which can vary wave power estimation (for example, Barbariol et al., 2013). In the case of Ireland, although generally not large around the coast, with the exception of some areas off the east and north (SEI, 2004), currents could play an important role in the accurate estimation of available wave power.

Quantifying how the wave climate of Ireland may change in the future is crucial for the long-term planning of largescale deployments of marine renewable energy installations, as well as other marine activities. The most recent climate projections in IPCC AR5 (Intergovernmental Panel on Climate Change Fifth Assessment Report, Collins et al., 2013) 
for the North Atlantic wind climate under CMIP5 (Coupled Model Intercomparison Project 5, Taylor et al., 2012), project an overall increase in mean sea-level pressure (MSLP) during winter and summer, fitting with slacker winds. The CMIP5 is a unified framework for co-ordinating global climate models (Taylor et al., 2012). It defines a series of experiments both multi-century and decadal under defined greenhouse gas (GHG) emission scenarios or Representative Concentration Pathways (RCP) (Moss et al., 2010). Various scenarios for changing GHG emissions have been defined: low (RCP2.6), medium-low (RCP4.5), medium (RCP6.0) and high (RCP8.5) emission scenarios. In general average wind changes over the North Atlantic Ocean by the end of the century have been found to be small and negative under climate warming, with the large natural variability of the region dominant (Collins et al., 2013).

Uncertainties in some aspects of the projections of future wind climate regimes, most notably in future storm track positioning, results in low confidence in wave climate projections for the North Atlantic region (Church et al., 2013; Woolf and Wolf, 2013). Studies used to examine the future wave climate have tended to consist of small numbers of ensembles with varying methodologies (Hemer et al., 2013a). However for example, studies such as those by the Coordinated Ocean Wave Climate Project (COWCLIP) (Hemer et al., 2013b) predict a reduction in mean annual, spring and summer SWH in the Northeast Atlantic by the end of the 21st century, consistent with the study presented in this paper. Global projections using CMIP5 models under the RCP4.5 and RCP8.5 emission scenarios (Dobrynin et al., 2012) and a 20-member ensemble of statistically modelled projections derived from CMIP5 data (Wang et al., 2014) also show a decrease in mean annual SWH for Atlantic mid-latitudes.

In summary, there is still large uncertainty in wave climate projections for the end of the twenty-first century for the North Atlantic region in general, and regionally for Ireland. There has not been any high resolution wave projection studies focused on the country. This study focuses specifically on Irish coastal waters with the finest resolution grid around Ireland varying in grid spacing from $15 \mathrm{~km}$ at the grid boundaries to $1 \mathrm{~km}$ in the nearshore. Using two CMIP5 GHG emission scenarios, RCP4.5 (medium-low) and RCP8.5 (high), the projected changes in surface wind speed over the North Atlantic for the end of the century were examined. This ensured that we could explore changes in the swell generating regions of the North Atlantic Ocean, which influence the Irish wave climate. The projected wave climate changes for Ireland were also examined, focusing on the seasonal changes in mean SWH. The projected spring and autumn changes for both RCP4.5 and RCP8.5 are investigated, whereas Gallagher et al. (2016b) focussed only on the summer and winter projections.

The paper is organised as follows: Section 2 provides details about the EC-Earth and WAVEWATCH III ${ }^{\circledR}$ models used in this study followed by a summary of the validation carried out in Gallagher et al. (2016b). In Sect. 3 the results are presented and discussed. In Sect. 4 we conclude the findings of this study.

\section{Model details and validation}

\subsection{EC-Earth}

The EC-Earth global climate model (version 2.3) used in this study consisted of an atmosphere-land surface module coupled to an ocean-sea ice module (Hazeleger et al., 2012). Its atmospheric component was based on cycle 31r1 of the European Centre for Medium-Range Weather Forecasts (ECMWF) Integrated Forecasting System and has a spectral resolution of T159L62 $\left(1.125^{\circ}\right.$ or $\sim 125 \mathrm{~km}$ grid spacing with 62 model levels). The Nucleus for European Modelling of the Ocean (version 2; Madec, 2008) was used for the oceanic component of the model (resolution $1^{\circ}$ or $\sim 110 \mathrm{~km}$ grid spacing with 42 vertical levels). The Louvain-la-Neuve Sea ice Model (version 2; Fichefet and Morales Maqueda, 1997) was used for the sea-ice module of the model. The OASIS (Ocean Atmosphere Sea Ice Soil) coupler (version 3; Valcke, 2006) was used for the two-way coupling between the atmosphere-land surface and ocean-sea ice components.

Three of the 14 EC-Earth ensemble members were available for use in this analysis and are representative of the spread of the ensemble. These ensemble members cover the range of interannual variability of the winds, although the spread of the EC-Earth ensemble mean annual wind speeds was not found to be large. Each member consists of an historical simulation and two future simulations (RCP4.5 and RCP8.5) and are denoted $m e i X, m e 4 X$ and $m e 8 X$ where $X=$ $1,2,3$ and denotes the ensemble number.

\subsection{WAVEWATCH III ${ }^{\circledR}$}

The WAVEWATCH III ${ }^{\circledR}$ (Tolman and the WAVEWATCH ${ }^{\circledR}$ III Development Group, 2014) model was used for the wave model simulations. We implemented three nested grids using a confined local area grid for Irish waters and two larger regional grids for the Northeast and North Atlantic Ocean, respectively. These grids are shown in Fig. 1. The North and Northeast Atlantic grids (a) and (b) in Fig. 1 were two-way nested. The finest resolution grid was run afterwards using the wave spectra output from the second grid to force it at its boundaries. Grid three, (c) in Fig. 1, was constructed using an unstructured grid formulation (Roland, 2008). Input and dissipation terms were formulated as in Ardhuin et al. (2010), tuned for the ECMWF global winds. For each of the three wave model grids shown in Fig. 1, simulations were driven by EC-Earth winds and sea ice fields from three historical, three RCP4.5 and three RCP8.5 ensemble members, respectively. Finally, one simulation was driven by ERA-Interim data to check the quality of the EC-Earth data in terms of capturing the present wind and wave climate. 

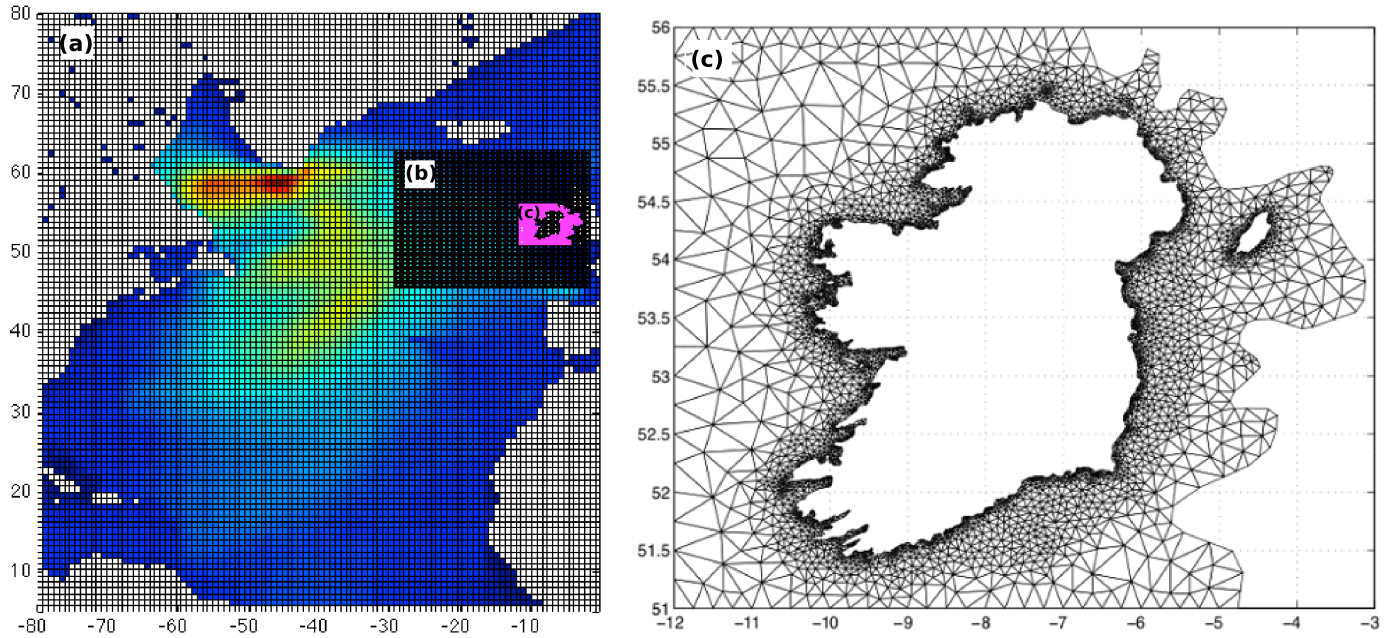

Figure 1. Left panel: the three wave model grids as described in Sect. 2.2. (a) The largest resolution North Atlantic grid has a $0.75^{\circ} \times 0.75^{\circ}$ resolution. (b) The grid for the Northeast Atlantic has a $0.25^{\circ} \times 0.25^{\circ}$ resolution. (c) The unstructured grid around Ireland has a resolution ranging from $15 \mathrm{~km}$ offshore to $1 \mathrm{~km}$ in the nearshore. Right panel: wave model unstructured grid used for the finest resolution domain around Ireland (c). This grid has 4473 nodes and the resolution varies from $15 \mathrm{~km}$ offshore to $1-2 \mathrm{~km}$ in the nearshore.

\subsection{Validation}

The validation carried out for this study is described in detail in Gallagher et al. (2016b), and a short summary is provided here. Overall, there is reasonable agreement (mostly within $\pm 10 \%$ ) between the 1981-2009 wind (means and percentiles) output from the EC-Earth historical ensemble and the ERA-Interim dataset, seasonally averaged over the North Atlantic basin. Wave buoy observations from the Irish Marine Weather Buoy Network, maintained by Met Éireann and the Marine Institute, were compared to the ERA-Interim driven wave model output (on the same grid as the wave projection simulations) and good agreement was found between the time-series with correlation coefficients of 0.93 or greater at each of the buoy locations examined. Seasonal differences of less than $\pm 5-10 \%$ were found for the ERAInterim driven wave model versus the historical EC-Earth driven wave model SWH (annual and seasonal), for the Atlantic and Celtic Sea regions. This was consistent across each individual ensemble member for the mean and 95th percentile of SWH.

\section{Results and discussion}

In this section we present the changes in the seasonal mean $10 \mathrm{~m}$ winds over the North Atlantic, and SWH off Irish Atlantic coasts, for the period 2070-2099 relative to 19802009. Although results for the Irish Sea are shown (off the east coast), they are excluded from our analysis. This is because the EC-Earth model grid has a spacing $(\sim 125 \mathrm{~km})$ of comparable size to the Irish Sea and the winds are considered too coarse in resolution to accurately drive a wave model for this region.

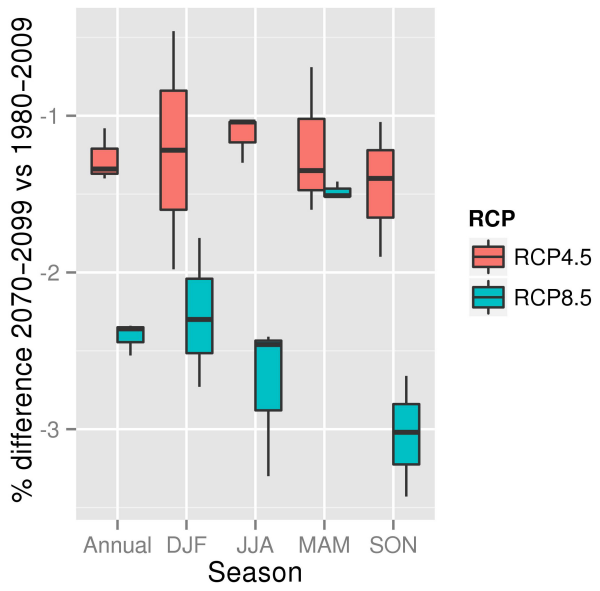

Figure 2. EC-Earth projected changes $(\%)$ in the mean $10 \mathrm{~m}$ wind speed over the North Atlantic Ocean for the period 2070-2099 relative to 1980-2009. Results for both the RCP4.5 (red) and RCP8.5 (blue) future climate scenarios are shown. The whiskers on the boxes show the spread of the results across the ensemble members (three RCP4.5 and three RCP8.5 members).

The projected changes (\%) in the EC-Earth mean $10 \mathrm{~m}$ wind speed averaged over the North Atlantic Ocean were estimated annually and for each season: winter (December, January, February; DJF hereafter); spring (March, April, May; MAM hereafter); summer (June, July August; JJA hereafter); and autumn (September, October, November; SON hereafter), for the period 2070-2099 (future) relative to 1980-2009 (historical). Results for both the RCP4.5 and RCP8.5 future climate scenarios are shown in Fig. 2. Similar to other CMIP5 experiments for the North Atlantic region 

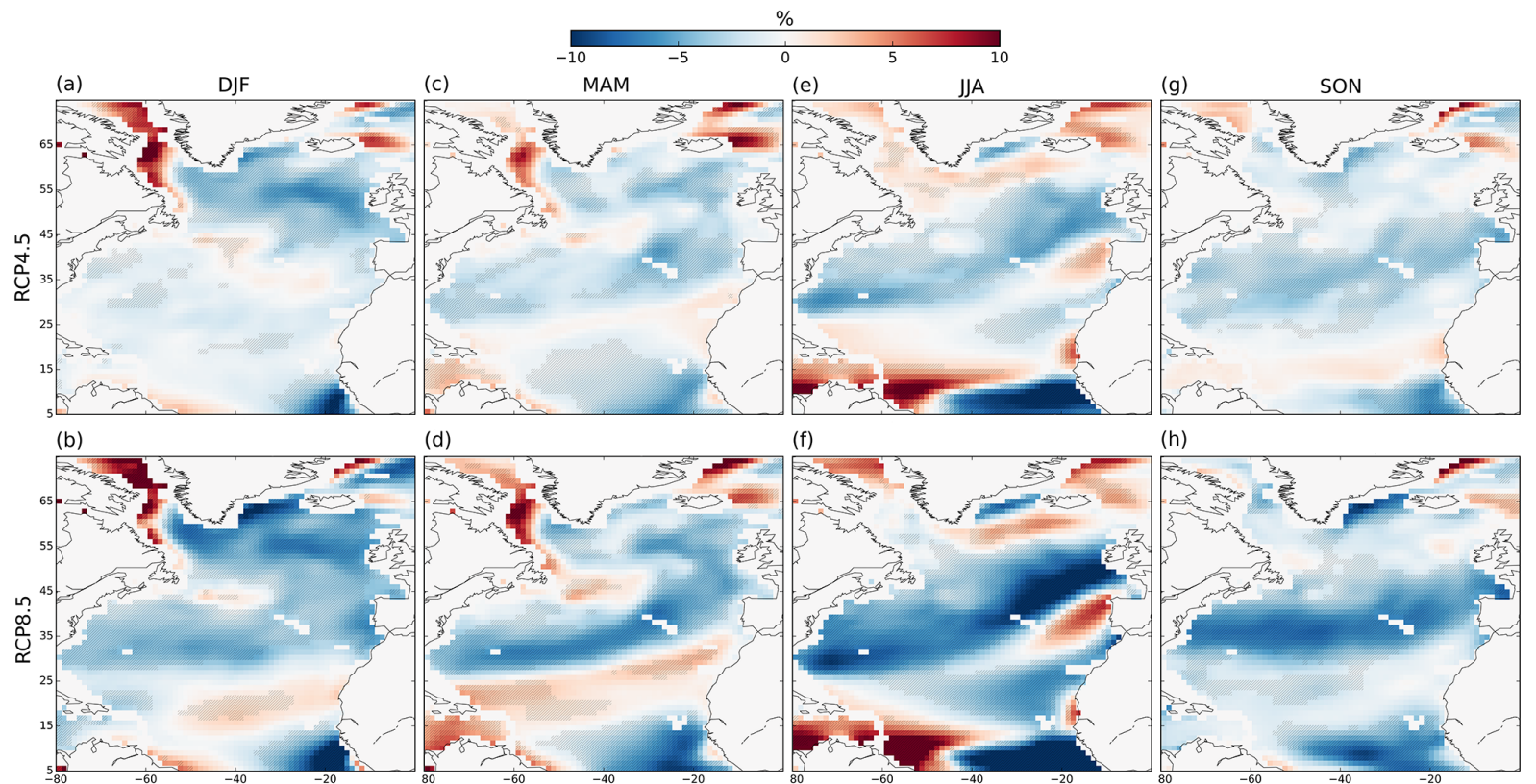

(d)

(f)

(h)
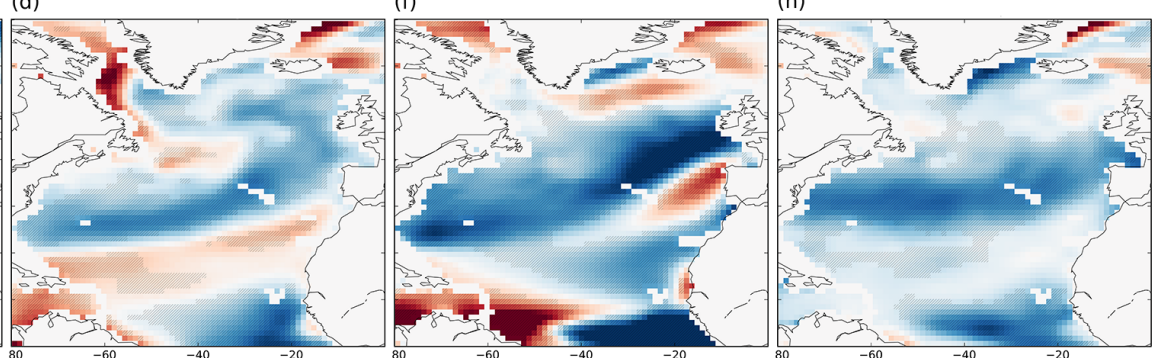

Figure 3. EC-Earth projected changes (\%) in $10 \mathrm{~m}$ wind speed over the North Atlantic Ocean for the period 2070-2099 relative to 19802009. Ensemble mean for RCP4.5: (a) DJF (c) MAM (e) JJA (g) SON. Ensemble mean for RCP8.5: (b) DJF (d) MAM (f) JJA (h) SON. Hatching covers areas where the changes are greater than twice the inter-ensemble standard deviation of the past period 1980-2009.

(Collins et al., 2013), we found a small decrease North Atlantic winds in DJF and JJA, as can be seen in Fig. 2. The whiskers on the boxes show the spread of the results across the ensemble members for each scenario. There are decreases of between $1-3 \%$ in the mean wind speed. Projected decreases in all of the wind speed percentiles (averaged over the North Atlantic) are presented in Gallagher et al. (2016b).

Examining the spatial distribution of these changes in Fig. 3 reveals a more diverse picture with regions of increasing and decreasing surface winds. This figure shows areal plots of the changes in the seasonal ensemble mean $10 \mathrm{~m}$ winds (ensembles of three members for both RCP4.5 and RCP8.5 scenarios) for the future relative to the historical period. Regions of relative decrease (negative changes, blue) can be seen in the swell generating areas for Ireland in the Northeast Atlantic for all seasons, for both scenarios, with larger decreases in the mean winds under the RCP8.5 scenario. This is particularly true for RCP8.5 DJF and JJA seasonal means where the decreases are more negatively pronounced (darker blue) and there are larger areas of statistical significance based on the following metric: where the change in the shown parameter exceeds twice the inter-ensemble standard deviation of the historical period 1981-2009, hatching is applied to the areal plot. This is also reflected in the more robust decreases found in SWH in Fig. 4 for these seasons. It should be noted that an ensemble of three members is small and a larger ensemble would be preferable in order to estimate a robust inter-ensemble spread (the hatching). However, the computational resources available to run the wave projections only enabled a limited set of wave model simulations to be run (ten 30-year simulations for each of the three nested wave model grids: an ERA-Interim hindcast and nine EC-Earth driven model runs as described in Sect. 2.1).

The changes in the ensemble mean SWH (three members for each RCP scenario) for the future relative to the historical period are presented in Fig. 4. The ensemble mean annual SWH in Fig. 4b and c shows a reduction of $5-10 \%$ off the Atlantic coastline under the RCP4.5 and RCP8.5 scenarios, with very little variation between the individual ensemble members (not shown). For DJF, as can be seen in Fig. $4 \mathrm{e}$ and $\mathrm{f}$, the mean SWH decreases by over $5 \%$ under RCP4.5 and by up to $10 \%$ for RCP8.5 off the west coast. In JJA, there are mean decreases of up to $15 \%$ off the south coast under RCP8.5 (Fig. 4l). The reduction in mean SWH for RCP4.5 in JJA is lower (Fig. 4k), at just over $5 \%$ off the south coast. Nevertheless, this reduction is still significant using the inter-model standard deviation test. The projections in MAM and SON show smaller, less robust decreases of between $1-4 \%$ in SWH under both scenarios (Fig. $4 \mathrm{~h}-\mathrm{i}$ and $4 n-0$, respectively). Off the west coast, the decrease in SWH under the RCP4.5 scenario for these seasons was not significant. These projected changes in SWH may consequently reduce the amount of wave power available for exploitation for any future deployments of WECs. However, as was shown in Gallagher et al. (2016a), Ireland possesses a large and energetic wave energy resource, particularly off the west coast, and this reduction is expected to have a minimal impact on 

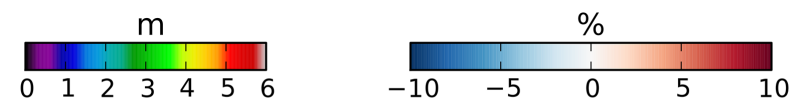

(a) Annual

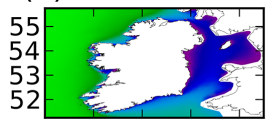

(d) DJF

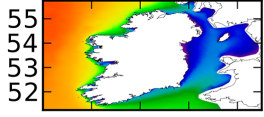

(g)

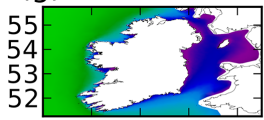

(j)

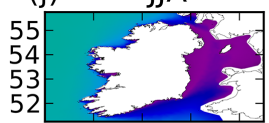

(m)

SON

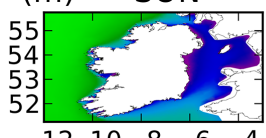

$-12-10-8-6-4$ (b) RCP4.5

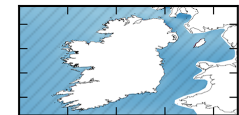

(e)

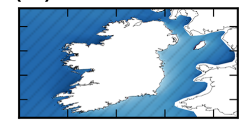

(h)

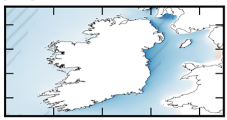

(k)

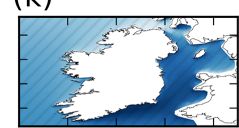

(n)

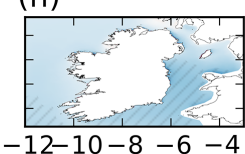

(c) RCP8.5

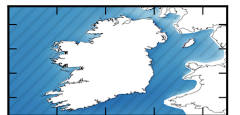

(f)

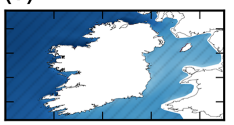

(i)

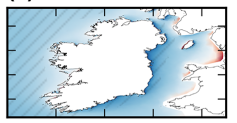

(I)

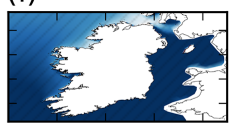

(o)

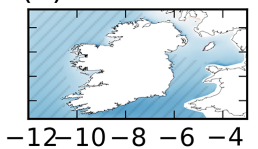

Figure 4. Ensemble mean SWH (m): (a) annual (d) DJF (g) MAM (j) JJA and (m) SON for the historical period (1980-2009). Projected changes $(\%)$ in annual ensemble mean SWH for the period 2070-2099 relative to 1980-2009 for ensemble mean RCP4.5: (b) annual (e) DJF (h) MAM (k) JJA (n) SON and ensemble mean RCP8.5: (c) annual (f) DJF (i) MAM (l) JJA and (o) SON. Hatching denotes areas where the magnitude of the ensemble mean change exceeds twice the inter-model standard deviation.

the overall potential for ocean renewable energy extraction in Ireland.

The geographical track of mid-latitude North Atlantic depressions crossing the region around Ireland $\left(50-57^{\circ} \mathrm{N}, 3-\right.$ $13^{\circ} \mathrm{W}$ ) for the future period relative to the historical was also examined in Gallagher et al. (2016b) and a summary of the findings are included here. Using a heuristic algorithm, low pressure systems were tracked using constraints on speed, direction of movement and the deepening rate. Based on the tracking, the number of depressions were counted for each ensemble member in the RCP8.5 scenario. A decrease in the frequency of depressions crossing this region was found for all depression counts examined (MSLP core minima ranging from 940 to $990 \mathrm{hPa}$ ). We found no evidence that the historical and future data samples of depressions were from differing distributions using a two-sample Kolmogorov-Smirnov test. It should also be noted that substantial uncertainty exists in the ability of CMIP5 models to project changes for Northern Hemisphere winter storm tracks in the North Atlantic Ocean (Church et al., 2013; Zappa et al., 2013).

\section{Conclusions}

Using the EC-Earth global climate model and the WAVEWATCH III ${ }^{\circledR}$ wave model we estimated how climate change might affect the wave climate around Ireland and the North Atlantic for the future period 2070-2099 relative to 19802009. We used three EC-Earth ensemble members, where each member consisted of an historical simulation and two future realisations for the RCP4.5 and RCP8.5 emission scenarios, respectively. EC-Earth MSLP fields were also used to examine how the number of depressions crossing Irish waters is projected to change towards the end of the century.

The EC-Earth ensemble projections show an average decrease in mean surface wind speeds over the North Atlantic Ocean for all seasons, greater under RCP8.5 than RCP4.5 which results in an average decrease in mean SWH for Ireland annually and for all seasons. The largest decreases were found off the south coast of Ireland in JJA (15\%) and off the west coast in DJF (10\%) for the RCP8.5 emissions scenario. The projected changes in mean SWH for MAM and SON are small and less robust than for DJF and JJA, and should be treated with caution due to the large natural variability in the wave climate of Ireland. No significant changes were found for MAM and SON off the west coast for the RCP4.5 scenario. The small number of ensemble members reduces the robustness of the estimated projections but nevertheless this is the first set of high resolution wave projections for Ireland.

Future work includes a plan to run a much larger multimodel ensemble, in order to improve the estimates of uncertainties. In addition, higher resolution driving data, such as that from the next suite of global climate simulations under CMIP6 might improve the representation of storm tracks and extremes in the wind and wave climate of the region. Any careful assessment of the future wave climate of Ireland should also consider both winds and WCI, and ideally be carried out using coupled atmosphere-wave-oceanic numerical models.

Author contributions. E. Gleeson performed and analysed the EC-Earth simulations. R. Tiron and S. Gallagher designed and performed the WAVEWATCH III ${ }^{\circledR}$ simulations. S. Gallagher analysed the WAVEWATCH III ${ }^{\circledR}$ simulations. R. McGrath developed the storm tracking algorithm code and implemented it on the ECEarth dataset. S. Gallagher and E. Gleeson analysed the storm tracking algorithm results. S. Gallagher and E. Gleeson prepared the manuscript with contributions from F. Dias.

Acknowledgements. The study was funded by Science Foundation Ireland (SFI) under the research project "High-end computational modelling for wave energy systems" (10/IN.1/I2996). The numerical simulations were performed on the Fionn cluster at the Irish Centre for High-end Computing (ICHEC) and at the Swiss National Computing Centre under the PRACE-2IP project (FP7 RI-283493) "Nearshore wave climate analysis of the west coast of 
Ireland". We also wish to thank the editor and two reviewers for their suggestions and comments.

Edited by: S. Carniel

Reviewed by: C. Sweeney and one anonymous referee

\section{References}

Ardhuin, F., Rogers, E., Babanin, A., Filipot, J.-F., Magne, R., Roland, A., van der Westhuysen, A., Queffeulou, P., Lefevre, J.M., Aouf, L., and Collard, F.: Semi-empirical dissipation source functions for wind-wave models: Part I, definition, calibration and validation, J. Phys. Oceanogr., 40, 1917-1941, 2010.

Barbariol, F., Benetazzo, A., Carniel, S., and Sclave, M.: Improving the assessment of wave energy resources by means of coupled wave-ocean numerical modeling, Renew. Energ., 60, 462-471, doi:10.1016/j.renene.2013.05.043, 2013.

Church, J., Clark, P., Cazenave, A., Gregory, J., Jevrejeva, S., Levermann, A., Merrifield, M., Milne, G., Nerem, R., Nunn, P., Payne, A., Pfeffer, W., Stammer, D., and Unnikrishnan, A.: Sea Level Change, in: Climate Change 2013: The Physical Science Basis. Contribution of Working Group I to the Fifth Assessment Report of the Intergovernmental Panel on Climate Change, edited by: Stocker, T. F., Qin, D., Plattner, G.-K., Tignor, M., Allen, S. K., Boschung, J., Nauels, A., Xia, Y., Bex, V., and Midgley, P. M., Cambridge University Press, Cambridge, United Kingdom and New York, NY, USA, 2013.

Collins, M., Knutti, R., Arblaster, J., Dufresne, J.-L., Fichefet, T., Friedlingstein, P., Gao, X., Gutowski, W. J., Johns, T., Krinner, G., Shongwe, M., Tebaldi, C., Weaver, A. J., and Wehner, M.: Long-term Climate Change: Projections, Commitments and Irreversibility, in: Climate Change 2013: The Physical Science Basis. Contribution of Working Group I to the Fifth Assessment Report of the Intergovernmental Panel on Climate Change, edited by: Stocker, T. F., Qin, D., Plattner, G.-K., Tignor, M., Allen, S. K., Boschung, J., Nauels, A., Xia, Y., Bex, V., and Midgley, P. M., Cambridge University Press, Cambridge, United Kingdom and New York, NY, USA, 2013.

Dobrynin, M., Murawsky, J., and Yang, S.: Evolution of the global wind wave climate in CMIP5 experiments, Geophys. Res. Lett., 39, L18606, doi:10.1029/2012GL052843, 2012.

Fichefet, T. and Morales Maqueda, M. A.: Sensitivity of a global sea ice model to the treatment of ice thermodynamics and dynamics, J. Geophys. Res., 102, 12609-12646, 1997.

Gallagher, S., Tiron, R., and Dias, F.: A long-term nearshore wave hindcast for Ireland: Atlantic and Irish Sea coasts, 1979-2012, Ocean Dynam., 64, 1163-1180, doi:10.1007/s10236-014-07283, 2014.

Gallagher, S., Tiron, R., Whelan, E., Gleeson, E., Dias, F., and McGrath, R.: The nearshore wind and wave energy potential of Ireland: a high resolution assessment of availability and accessibility, Renew. Energ., 88, 494-516, doi:10.1016/j.renene.2015.11.010, 2016a.

Gallagher, S., Gleeson, E., Tiron, R., Dias, F., and McGrath, R.: Wave Climate Projections for Ireland for the end of the TwentyFirst Century including analysis of EC-Earth winds over the North Atlantic Ocean, Int. J. Climatol., doi:10.1002/joc.4656, in press, $2016 \mathrm{~b}$.
Hazeleger, W., Wang, X., Severijns, C., Ştefănescu, S., Bintanja, R., Sterl, A., Wyser, K., Dutra, E., Baldasano, J. M., Bintanja, R., Bougeault, P., Caballero, R., Ekman, A. M. L., Christensen, J. H., van den Hurk, B., Jimenez, P., Jones, C., Kållberg, P., Koenigk, T., McGrath, R., Miranda, P., Van Noije, T., Palmer, T., Parodi, J. A., Schmith, T., Selten, F., Storelvmo, T., Sterl, A., Tapamo, H., Vancoppenolle, M., Viterbo, P., and Willén, U.: EC-Earth V2. 2: description and validation of a new seamless earth system prediction model, Clim. Dynam., 39, 2611-2629, 2012.

Hemer, M. A., Katzfey, J., and Trenham, C. E.: Global dynamical projections of surface ocean wave climate for a future high greenhouse gas emission scenario, Ocean Model, 70, 221-245, 2013a.

Hemer, M. A., Fan, Y., Mori, N., Semedo, A., and Wang, X. L.: Projected changes in wave climate from a multi-model ensemble, Nat. Clim. Change, 3, 471-476, 2013b.

Madec, G.: NEMO ocean engine. Note du Pole de modélisation, No. 27, Institut Pierre-Simon Laplace (IPSL), France, ISSN: 12881619, 2008.

Moss, R. H., Edmonds, J. A., Hibbard, K. A., Manning, M. R., Rose, S. K., van Vuuren, D. P., Carter, T. R., Emori, S., Kainuma, M., Kram, T., Meehl, G. A., Mitchell, J. F. B., Nakicenovic, N., Riahi, K., Smith, S. J., Stouffer, R. J., Thomson, A. M., Weyant, J. P., and Wilbanks, T. J.: The next generation of scenarios for climate change research and assessment, Nature, 463, 747-756, 2010.

Roland, A.: Development of WWM (Wind Wave Model) II: Spectral wave modelling on unstructured meshes, $\mathrm{PhD}$ thesis, Institute of Hydraulics and Wave Resource Engineering, Technical University Darmstadt, Germany, 2008.

Sustainable Energy Ireland (SEI): Tidal \& Current Energy Resources in Ireland, http://www.seai.ie/Publications/Renewables_ Publications_/Ocean/Tidal_Current_Energy_Resources_in_ Ireland_Report.pdf (last access: 14 April 2016), Technical report, Sustainable Energy Ireland, 2004.

Taylor, K. E., Stouffer, R. J., and Meehl, G. A.: An Overview of CMIP5 and the experiment design, B. Am. Meteorol. Soc., 93, 485-498, doi:10.1175/BAMS-D-11-00094.1, 2012.

Tolman, H. and the WAVEWATCH ${ }^{\circledR}$ III Development Group: User manual and system documentation of WAVEWATCH III version 4.18, Technical Report 316, NOAA/NWS/NCEP/MMAB, 2014.

Valcke, S.: OASIS3 User Guide (prism 2-5), CERFACS Technical Report TR/CMGC/06/73, CERFACS, Toulouse, France, 60 pp., 2006.

Wang, X. L., Feng, Y., and Swail, V. R.: Changes in global ocean wave heights as projected using multimodel CMIP5 simulations, Geophys. Res. Lett., 41, 1026-1034, doi:10.1002/2013GL058650, 2014.

Woolf, D. and Wolf, J.: Impacts of climate change on storms and waves, MCCIP Science Review 2013, 20-26, doi:10.14465/2013.arc03.020-026, 2013.

Zappa, G., Shaffrey, L. C., Hodges, K. I., Samson, P. G., and Stephenson, D. B.: A multimodel assessment of future projections of North Atlantic and European extratropical cyclones in the CMIP5 climate models, J. Climate, 26, 5846-5862, doi:10.1175/JCLI-D-12-00573.1, 2013. 